\title{
Epilepsy surgery for epileptic encephalopathy as a sequela of herpes simplex encephalitis: case report
}

\author{
Birce Dilge Taskin, MD, ${ }^{1}$ Kurenai Tanji, MD, PhD, ${ }^{2}$ Neil A. Feldstein, MD, ${ }^{3}$ \\ Maureen McSwiggan-Hardin, DNP, NP-P, ${ }^{4}$ and Cigdem I. Akman, MD ${ }^{5}$
}

\begin{abstract}
'Department of Pediatric Neurology, Ankara Children's Hematology Oncology Training and Research Hospital, Ankara, Turkey; and ${ }^{2}$ Department of Pathology and Cell Biology, Division of Neuropathology; ${ }^{3}$ Department of Neurosurgery; ${ }^{4}$ Department of Psychiatry, Division of Child Psychiatry; and ${ }^{5}$ Department of Neurology, Division of Child Neurology, Columbia University Medical Center, New York
\end{abstract}

\begin{abstract}
Herpes simplex virus (HSV) encephalitis can manifest with different clinical presentations, including acute monophasic illness and biphasic chronic granulomatous HSV encephalitis. Chronic encephalitis is much less common, and very rare late relapses are associated with intractable epilepsy and progressive neurological deficits with or without evidence of HSV in the cerebrospinal fluid. The authors report on an 8-year-old girl with a history of treated HSV-1 encephalitis when she was 13 months of age and focal epilepsy when she was 2 years old. Although free of clinical seizures, when she was 5 , she experienced behavioral and academic dysfunction, which was later attributed to electrographic focal seizures and worsening electroencephalography (EEG) findings with electrical status epilepticus during slow-wave sleep (ESES). Following a right temporal lobectomy, chronic granulomatous encephalitis was diagnosed. The patient's clinical course improved with the resolution of seizures and EEG abnormalities.
\end{abstract}

https://thejns.org/doi/abs/10.3171/2017.3.PEDS16632

KEY WORDS epilepsy surgery; herpes simplex virus encephalitis; ESES; epileptic encephalopathy

I NFECTION of the central nervous system (CNS) caused by herpes simplex virus (HSV) requires prompt diagnosis and urgent medical attention for treatment. ${ }^{13}$ Herpetic encephalitis is often seen as a monophasic acute disease caused by HSV Types 1 and 2 (HSV-1 and HSV-2). The typical clinical presentation is acute encephalopathy and fever in adults and older children, but seizures, lethargy, and fever in infants and younger children. Unfortunately, a small proportion of patients diagnosed with HSV encephalitis can present with clinical deterioration or relapse over a varied length of time. The viral antigen and its DNA can be detected in the brain tissue or cerebrospinal fluid (CSF) in the recurrent/relapsing form of HSV encephalitis, and acyclovir remains the treatment of choice..$^{10,13,18}$ The diagnosis of HSV encephalitis can be more complex because in some cases, culture, immunohistochemical, and poly- merase chain reaction (PCR) studies are negative because of a postinfectious immune mechanism. ${ }^{18}$

In other cases, a progressive clinical course with worsening neurological deficits and seizures can be seen following the initial diagnosis of HSV encephalitis. ${ }^{6,10}$ This clinical course is called "chronic granulomatous HSV encephalitis," which presents as a biphasic disease. ${ }^{13}$ Pathological findings are granulomatous inflammation with multinucleated giant cells, gliosis, and multifocal mineralization in the brain parenchyma specimen. ${ }^{10,13}$

In this report, we describe an 8-year-old girl with a history of previously treated HSV-1 encephalitis who later developed focal epilepsy. Progressive worsening of her behavior and academic functioning were attributed to her electrographic seizures and worsening electroencephalography (EEG) findings accompanied by electrical status

ABBREVIATIONS BBB = blood-brain barrier; $C N S=$ central nervous system; CSF = cerebrospinal fluid; ECoG = electrocorticography; EEG = electroencephalography; ESES = electrical status epilepticus in slow-wave sleep; HSV = herpes simplex virus; NREM = nonrapid eye movement; PCR = polymerase chain reaction; TLR = Toll-like receptor.

SUBMITTED November 15, 2016. ACCEPTED March 10, 2017.

INCLUDE WHEN CITING Published online April 28, 2017; DOI: 10.3171/2017.3.PEDS16632. 

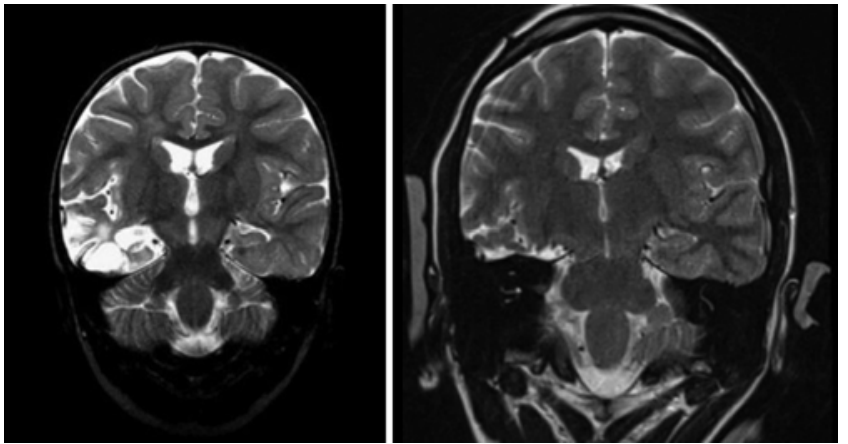

FIG. 1. Brain MRI studies obtained when the patient was 15 months of age, demonstrating cystic encephalomalacia and hippocampal atrophy of the right temporal lobe (left) and right mesial temporal sclerosis (right).

epilepticus in slow-wave sleep (ESES). Resective epilepsy surgery was performed to remove encephalomalacia located in the right temporal and inferior parietal lobes. Electroencephalography and clinical features demonstrated improvement after epilepsy surgery with resolution of the ESES. Pathological analysis of the surgical substrate revealed the diagnosis of chronic granulomatous encephalitis. Her past medical and family history did not contribute to her diagnosis.

\section{Case Report}

\section{History and Examination}

At the age of 13 months, a female presented with fever, drowsiness, and focal status epilepticus. Polymerase chain reaction testing of the CSF revealed the diagnosis of acute HSV-1 encephalitis. Intravenous acyclovir therapy $(10 \mathrm{mg} /$ $\mathrm{kg}$ every 8 hours) was administered for 14 days. Magnetic resonance imaging of her brain was performed 2 months later and displayed evidence of encephalomalacia in the right temporal and parietal lobes in addition to right mesi- al temporal sclerosis (Fig. 1). At the age of 2, she presented with staring, eye blinking, and lip smacking, with left-sided jerking during the febrile illness. She became seizure free on lamotrigine. At the age of 5, despite seizure freedom, she began to experience academic dysfunction and a worsening attention span and to display aggressive behavior. Her EEG demonstrated abundant focal spike discharges with maximum amplitude in the right temporal regions in nonrapid eye movement (NREM) sleep, occupying $60 \%$ of NREM sleep recording (Fig. 2). When she was 6, follow-up EEG recording demonstrated an increasing frequency in spike discharges, occupying $90 \%$ of the NREM sleep, which suggested the diagnosis of ESES (Fig. 3). A 3 -week course of high-dose benzodiazepine treatment improved her EEG findings and decreased the frequency of spikes to less than $1 \%$ compared with her previous EEG findings. When she was 7, her behavior worsened over 6 months, which was concurrent with tics, clapping, grunting, eye blinking, and impulsive and aggressive behavior toward her teachers and friends. Repeat EEG demonstrated focal spike discharges and electrographic seizures arising from the right temporal and parietal regions in sleep (Fig. 4). The worsening course of the clinical and EEG features supported the diagnosis of epileptic encephalopathy. She was switched from lamotrigine to levetiracetam to control her seizures and the worsening course of the baseline EEG findings. Despite the dose adjustments, the EEG findings remained unchanged. Subsequently, highdose benzodiazepine was administered, which promptly resolved the ESES and electrographic seizures. Following a stable course of 6 months, a worsening clinical course, and the return of ESES, the high-dose benzodiazepine was stopped. There was $20 \%$ improvement in the ESES disease pattern without a significant improvement in seizures.

When she was 8, a number of diagnostic tests were performed to localize the EEG findings and seizures compromising left hemisphere function. A magnetoencephalog-

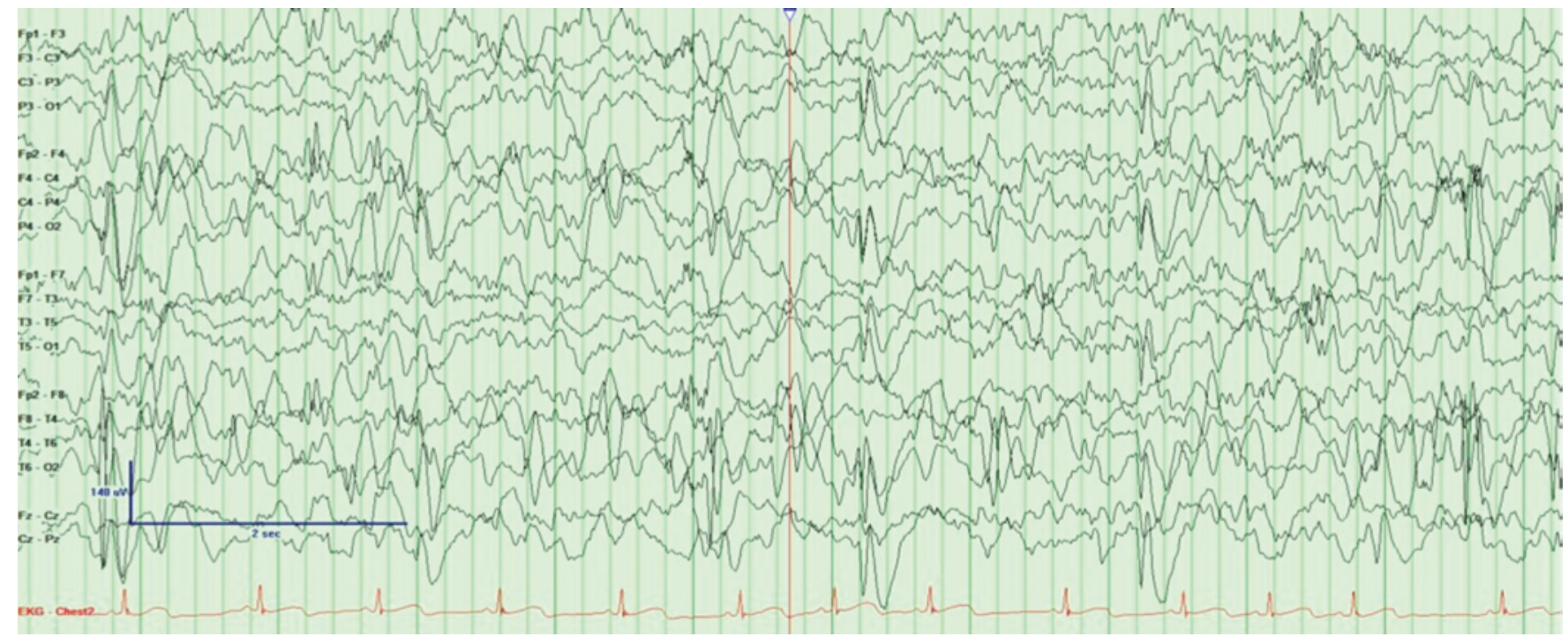

FIG. 2. When the patient was 5 years old, her sleep EEG recordings showed abundant focal spike discharges with maximum amplitude in the right temporal regions. Figure is available in color online only. 


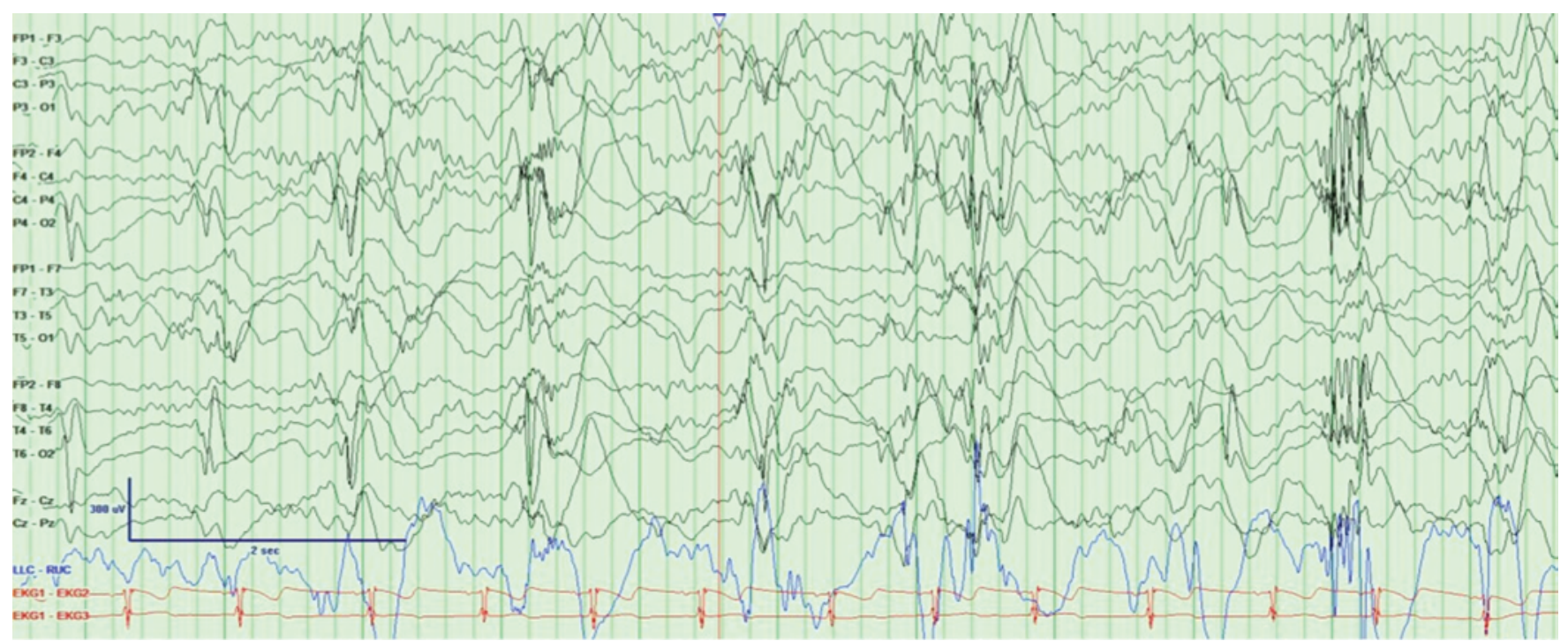

FIG. 3. When she was 6 years old, her EEG recordings showed high-amplitude focal spike and polyspike discharges with a field to the left hemisphere in NREM sleep $(1 \mathrm{~Hz}, 300-400 \mu \mathrm{V})$. Figure is available in color online only.

raphy study demonstrated two dipole patterns, one located in the right posterior temporal lobe and the second in the anterior temporal lobe involving the mid-frontal region. Indeed, at times these dipole patterns overlapped starting from the posterior temporal region and developing anterior temporal mid-frontal dipole. Positron emission tomography revealed decreased glucose metabolism only in the left hemisphere sparing the right occipital regions and predominantly seen in the right temporal and parietal cortex. Repeat brain MRI with gadolinium did not reveal any significant change in encephalomalacia or cortical enhancement. Functional brain MRI was performed, and language function was mapped to the left hemisphere.
Considering the patient's clinical course with worsening behavior and academic difficulties, her case was presented at our epilepsy surgery conference to explore a surgical treatment option for her.

After the surgery conference, we believed that the presence of epileptiform discharges was indeed affecting her overall cognitive functions, social interactions, and behavior, although no obvious clinical seizure was documented in the earlier studies when she had been admitted to the hospital for video EEG monitoring. At this point, we believed that epilepsy surgery could prevent further decline in her cognitive functioning and prevent left hemispheric dysfunction, especially language functions, because of the

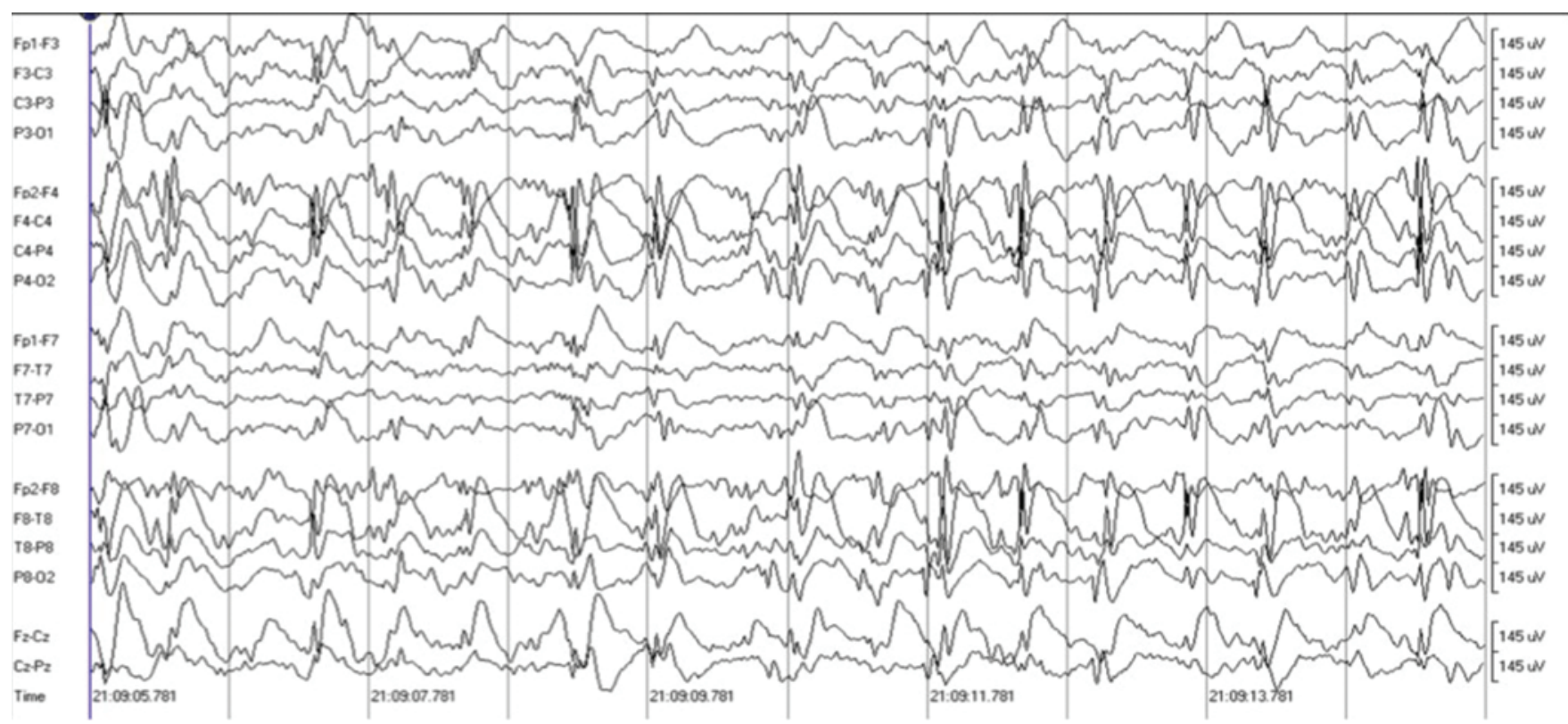

FIG. 4. When she was 7 years old, repeat EEG showed electrographic seizures in the right hemisphere. Figure is available in color online only. 

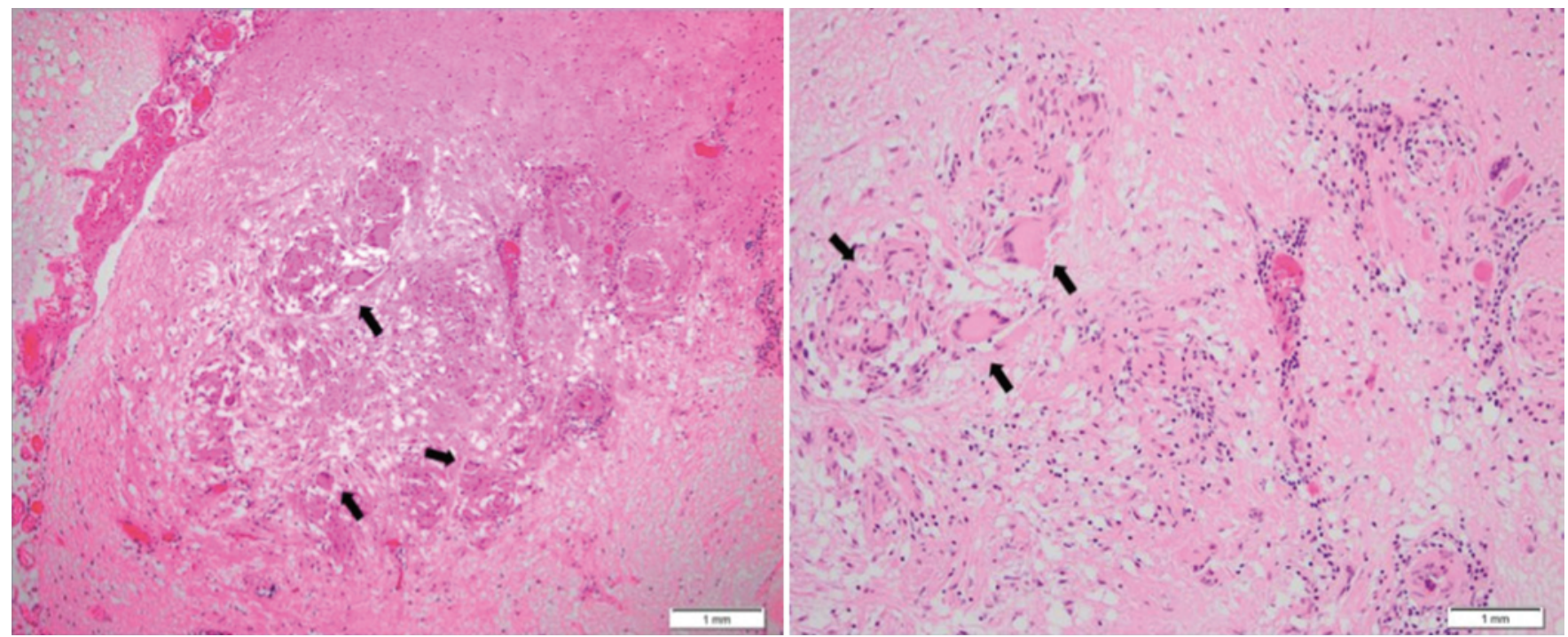

FIG. 5. Photomicrographs showing multiple foci of granulomatous chronic inflammation containing many multinucleated giant cells (arrows) in the background of neuronal loss and extensive gliomesenchymal scarring in the brain parenchyma. $\mathrm{H} \& \mathrm{E}$, original magnification $\times 100$ (left) and $\times 200$ (right). Figure is available in color online only.

presence of frequent epileptiform discharges mostly involving her slow-wave sleep. We also believed that there was no need for invasive video EEG monitoring via subdural electrodes. The patient was scheduled for electrocorticography $(\mathrm{ECoG})$-guided resection of the temporal lobe.

\section{Surgical Procedure}

An L-shaped incision was made to expose the frontotemporal and parietal regions with the incision starting in the region of the mastoid and staying to the right of the middle superiorly. Electrocorticography was performed after 6-contact strip electrode was placed over the inferior parietal, temporal, and inferior frontal cortex. Frequent spike and polyspike discharges were seen in all recorded areas. The gyrus involving extension of the MRI abnormality into the inferior parietal region was resected in a subpial manner. Then resection of the temporal tissue was performed, extending up to the level of the sylvian fissure pia-arachnoid. Once the neocortex was resected, the ventricle was entered for resection of the medial temporal tissue. Much of the tissue in the resected area was clearly abnormal, being somewhat boggy and liquefied, and portions were quite abnormally formed. Resection included the parahippocampal gyrus back to the level of the atrium. Posteriorly, the resection continued until normal-appearing white and gray matter was encountered. Once all the apparently abnormal tissue was removed, ECoG was then performed. Subsequently, postresection ECoG was performed, demonstrating the resolution of spike discharges in the inferior parietal lobe. The spike discharges were still present in the inferior frontal region.

Acyclovir prophylaxis was administered one night before the surgery to prevent a possible HSV infection reactivation.

\section{Neuropathology}

The neuropathological examination of the right anterior temporal specimen and right hippocampus demonstrated highly distorted brain parenchyma with cavitation, severe neuronal loss, tissue edema, extensive gliomesenchymal scarring, and marked hemosiderin deposits indicating previous hemorrhage(s). In the distorted parenchyma, there were multiple foci of mineralization with and without foreign body giant cell reaction and chronic inflammation. The inflammatory cells consisted mainly of $\mathrm{T}$ cells (CD3+). Multinucleated giant cells were CD68 immunoreactive, and staining also highlighted activated microglia in surrounding tissue. Immunohistochemical staining for viral antigens including HSV-1 and HSV-2 were negative. No HSV-1 DNA was detected in the brain tissue using PCR analysis of paraffin sections. However, the neuropathological findings raised a high possibility of chronic granulomatous HSV encephalitis (Fig. 5).

\section{Postoperative Course}

The patient's postoperative course was uneventful. Her EEG recordings 6 months after surgery demonstrated the resolution of spikes and seizures (Fig. 6). There was significant improvement in her aggressive and impulsive behavior. Her attention span improved. She has remained seizure free with stable EEG findings for the last 8 years. Her parents opted for clobazam to prevent potential seizure recurrence in the future. Postsurgery brain MRI demonstrated removal of the right temporal lobe (Fig. 7).

Two months before and 8 months after the epilepsy surgery, neuropsychological assessment was performed using the Wechsler Intelligence Scale for Children-Fourth Edition (WISC-IV) to evaluate her cognitive abilities. Prior to surgery, Full Scale IQ (FSIQ) was 81, processing speed 83 (13\%), working memory 83 (13\%), and perceptual reasoning 73 (2\%). Following surgery, FSIQ increased to 88, processing speed to $97(42 \%)$, and working memory to 91 $(27 \%)$. Overall cognitive profile on the WISC-IV represented an increase in functioning from low-average to average range. Her visual memory improved from impaired range to average range after surgery, although her immedi- 


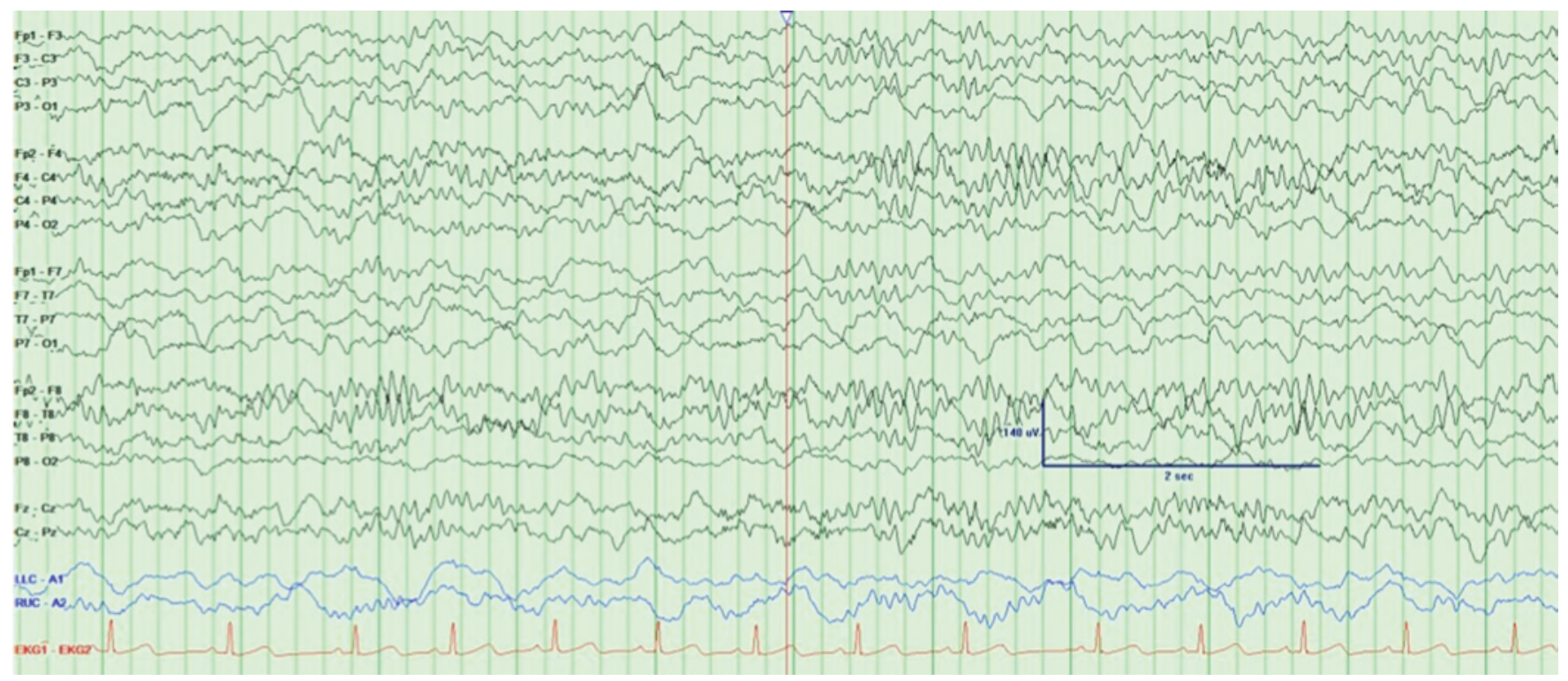

FIG. 6. Electroencephalography tracings following epilepsy surgery, with the resolution of spikes and seizures (sensitivity: $7 \mu \mathrm{v} /$ $\mathrm{mm}$, high frequency: $70 \mathrm{~Hz}$, low frequency: $1 \mathrm{~Hz}$ ). Figure is available in color online only.

ate recall remained in the impaired range. As regards her behavior, the patient exhibited disinhibition and impaired attention and concentration before surgery. After surgery, her impulsive behavior improved and the application of Conners' Continuous Performance Test demonstrated no evidence for a diagnosis of attention-deficit hyperactivity disorder.

\section{Discussion}

Herpes simplex virus encephalitis is generally an acute monophasic disease in which late relapses are uncommon. Rarely, the HSV infection leads to a chronic progressive

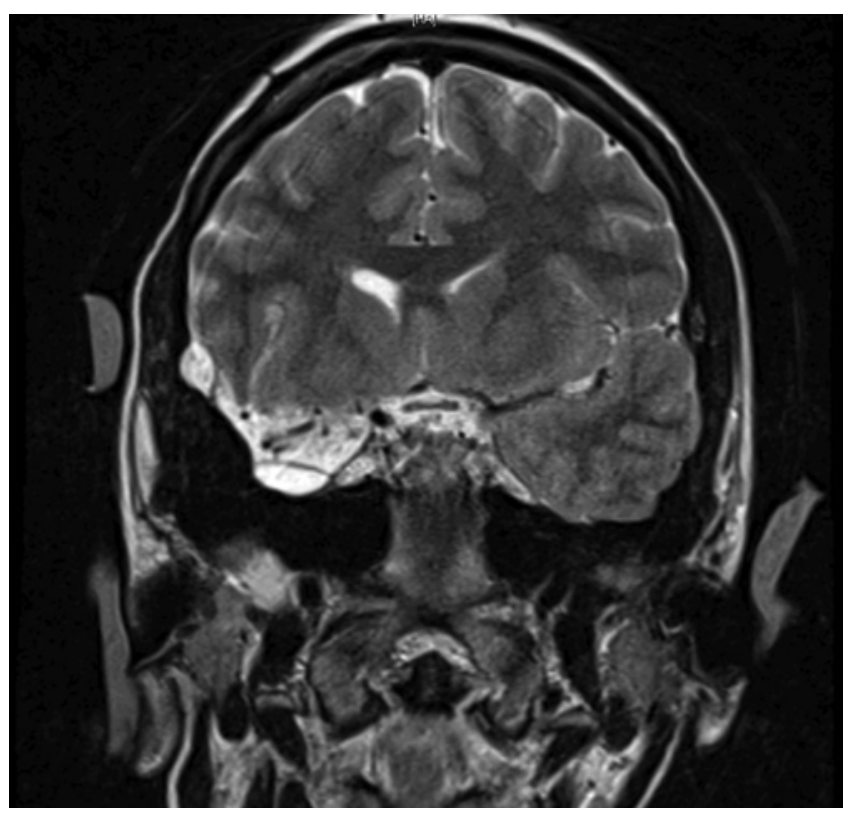

FIG. 7. Postoperative coronal T2-weighted MR image demonstrating removal of the right temporal lobe. encephalitic disease that usually manifests with intractable seizures and progressive neurological deficits with or without evidence of HSV in the CSF. ${ }^{1,6,10}$

To the best of our knowledge, 11 patients with chronic granulomatous encephalitis following an initial diagnosis of acute HSV encephalitis have been reported; however, the exact prevalence of such cases remains unknown. Neuropathological examination of brain tissues is required for the diagnosis of this disease, which is characterized by granulomas consisting of epithelioid macrophages and large multinucleated giant cells that are surrounded by mononuclear inflammatory cells with a prominent plasma cell component, chronic inflammation, and gliosis with extensive mineralization. ${ }^{1,4,6,7,10,13,18}$ Chronic granulomatous encephalitis associated with HSV infection generally presents with a biphasic course in older children. ${ }^{1,6,10,18}$ Viñas et al. ${ }^{18}$ described a previously healthy girl who developed HSV-1 encephalitis at the age of 8 years old. After remaining asymptomatic for 8 months, she began to complain of intracranial hypertension symptoms such as headache, vomiting, diplopia, and bilateral papilledema. One year later, a neuropathological study revealed chronic granuloma with giant cells, gliosis, and calcification, which was diagnosed as chronic granulomatous encephalitis.

A monophasic course of chronic HSV-1 encephalitis is described in younger children. Four infants who had been diagnosed with HSV encephalitis when they were neonates later developed multicystic encephalomalacia., ${ }^{4,710,13}$ This entity suggests that granulomatous HSV encephalitis in infants develops in a different, more severe way. In the literature, there is an apparent history of HSV encephalitis in infancy and a years-later presentation of intractable epilepsy, which can easily be attributed to encephalomalacia as a result of the initial HSV encephalitis (Table 1).

We believe that our case represents a monophasic course of HSV-1 encephalitis with the development of focal epilepsy when she was 2 years old as a result of the HSV-1 
TABLE 1. Previously reported neuropathologically proven cases of infantile granulomatous herpes encephalitis

\begin{tabular}{|c|c|c|c|c|c|c|}
\hline $\begin{array}{l}\text { Authors } \\
\& \text { Year }\end{array}$ & $\begin{array}{c}\text { Age at } \\
\text { Diagnosis } \\
\text { of HSV } \\
\text { Encephalitis }\end{array}$ & $\begin{array}{c}\text { Clinical } \\
\text { Presentation }\end{array}$ & $\begin{array}{c}\text { Age at } \\
\text { Onset } \\
\text { of } \\
\text { Seizures }\end{array}$ & $\begin{array}{l}\text { Age at } \\
\text { Neuropathological } \\
\text { Diagnosis }\end{array}$ & Pathology & $\begin{array}{l}\text { Seizure Freedom } \\
\quad \& \text { Outcome }\end{array}$ \\
\hline $\begin{array}{l}\text { Chang et } \\
\quad \text { al., } 1990\end{array}$ & 3 wks & $\begin{array}{l}\text { Fever, lethargy, sei- } \\
\text { zures, hypotonia }\end{array}$ & 4 wks & 18 wks (postmortem) & $\begin{array}{l}\text { Multicystic encephalopathy, giant } \\
\text { cells, gliosis, mineralization }\end{array}$ & Patient died \\
\hline \multirow[t]{2}{*}{$\begin{array}{l}\text { Jay et al., } \\
1995\end{array}$} & $1 \mathrm{wk}$ & Intractable seizures & $1 \mathrm{wk}$ & 15 wks (postmortem) & $\begin{array}{l}\text { Multicystic encephalopathy, glio- } \\
\text { sis, extensive mineralization }\end{array}$ & Patient died \\
\hline & $7 \mathrm{mos}$ & Intractable seizures & $1.5 \mathrm{yrs}$ & $\begin{array}{l}3 \text { yrs (temporal lobec- } \\
\text { tomy/epilepsy surgery) }\end{array}$ & $\begin{array}{l}\text { Giant cells, gliosis, mineraliza- } \\
\text { tion }\end{array}$ & Data not provided in report \\
\hline \multirow[t]{3}{*}{$\begin{array}{l}\text { Love et al., } \\
\qquad 2004\end{array}$} & 2 wks & $\begin{array}{l}\text { Skin blisters, sudden } \\
\text { death }\end{array}$ & $\begin{array}{l}\text { No sei- } \\
\text { zures }\end{array}$ & 11 wks (postmortem) & $\begin{array}{l}\text { Multicystic encephalopathy, giant } \\
\text { cells, lymphocytic infiltrates, } \\
\text { mineralization }\end{array}$ & Patient died \\
\hline & $18 \mathrm{mos}$ & Intractable seizures & $2 \mathrm{yrs}$ & $\begin{array}{l}6 \text { yrs (functional } \\
\text { hemispherectomy/epi- } \\
\text { lepsy surgery, block } \\
\text { of temporal lobe taken } \\
\text { for histology) }\end{array}$ & $\begin{array}{l}\text { Gliosis, giant cells, lymphocytic } \\
\text { infiltrates, mineralization }\end{array}$ & $\begin{array}{l}\text { Rt hemiparesis, rare, far } \\
\text { less disabling seizures }\end{array}$ \\
\hline & $4.5 \mathrm{mos}$ & Intractable seizures & $2 \mathrm{yrs}$ & $\begin{array}{l}10 \text { yrs (temporal lobec- } \\
\text { tomy/epilepsy surgery) }\end{array}$ & $\begin{array}{l}\text { Gliosis, giant cells, lymphocytic } \\
\text { infiltrates, mineralization }\end{array}$ & $\begin{array}{l}\text { Seizure free, mild residual } \\
\text { It hemiparesis }\end{array}$ \\
\hline $\begin{array}{l}\text { Viñas et } \\
\quad \text { al., } 2006\end{array}$ & $8 \mathrm{yrs}$ & $\begin{array}{l}\text { Intracranial hyper- } \\
\text { tension symptoms } \\
\text { (headache, vomit- } \\
\text { ing, diplopia, bilat } \\
\text { papilledema) }\end{array}$ & $\begin{array}{l}\text { No sei- } \\
\text { zures }\end{array}$ & $\begin{array}{l}9 \text { yrs (stereotactic biopsy } \\
\text { from insular lesion) }\end{array}$ & $\begin{array}{l}\text { Gliosis, giant cells, mineraliza- } \\
\text { tion }\end{array}$ & $\begin{array}{l}\text { Making similar progress at } \\
\text { school as her peers, no } \\
\text { learning disability }\end{array}$ \\
\hline $\begin{array}{l}\text { Adamo et } \\
\quad \text { al., } 2011\end{array}$ & $6 \mathrm{mos}$ & Intractable seizures & 5 yrs & $\begin{array}{l}14 \text { yrs (excisional biopsy } \\
\text { of lesional area) }\end{array}$ & $\begin{array}{l}\text { Giant cells, gliosis, necrosis, } \\
\text { mineralization }\end{array}$ & $\begin{array}{l}\text { Seizure free w/ } 1 \text { anticon- } \\
\text { vulsant }\end{array}$ \\
\hline $\begin{array}{l}\text { Hackney } \\
\text { et al., } \\
2012\end{array}$ & $4 \mathrm{mos}$ & Intractable seizures & $6 \mathrm{mos}$ & $\begin{array}{l}10 \text { yrs (frontal lobectomy/ } \\
\text { epilepsy surgery) }\end{array}$ & $\begin{array}{l}\text { Gliosis, giant cells, necrosis, } \\
\text { mineralization }\end{array}$ & $\begin{array}{l}\text { Seizure free for } 1 \mathrm{mo} \text {, } \\
\text { followed by sev- } \\
\text { eral seizures per day w/ } \\
\text { multiple anticonvulsants }\end{array}$ \\
\hline $\begin{array}{l}\text { Schutz et } \\
\quad \text { al., } 2014\end{array}$ & 8 wks & Lethargy, seizures & 9 wks & 10 wks (postmortem) & $\begin{array}{l}\text { Multicystic encephalopathy, giant } \\
\text { cells, lymphocytic infiltrates, } \\
\text { mineralization }\end{array}$ & Patient died \\
\hline $\begin{array}{l}\text { Current } \\
\text { study }\end{array}$ & $13 \mathrm{mos}$ & $\begin{array}{r}\text { Seizures \& EEG ab- } \\
\text { normality (ESES) }\end{array}$ & $2 \mathrm{yrs}$ & $\begin{array}{l}8 \text { yrs (temporal lobec- } \\
\text { tomy/epilepsy surgery) }\end{array}$ & $\begin{array}{l}\text { Severe gliosis, giant cells, exten- } \\
\text { sive mineralization }\end{array}$ & $\begin{array}{l}\text { Seizure free w/ } 1 \text { anticon- } \\
\text { vulsant }\end{array}$ \\
\hline
\end{tabular}

encephalitis. The negative PCR result for HSV infection ruled out the possibility of recurrent HSV encephalitis presenting with a biphasic course. Therefore, the patient's clinical deterioration along with her behavioral problems and academic difficulties was attributed to frequent electrographic seizures and the development of ESES over time.

Although the underlying explanation for the chronic granulomatous encephalitis in our patient remains unclear, growing evidence in the literature suggests the role of inflammation in epileptogenesis..$^{11,17,19,20}$ Precipitating insults such as trauma, stroke, CNS infections (for example, HSV encephalitis), and autoimmune disorders result in the activation of brain parenchymal cells, endothelial cells of the blood-brain barrier (BBB), and leukocytes. These cells produce and release inflammatory mediators in the brain. Cytokines and danger signals (endogenous ligands released by damaged or stressor-activated cells) induce inflammatory molecules responsible for the direct activation of glial or neuronal signaling pathways and BBB break- down. Inflammatory mediators can activate neurotransmitter release and glutamate receptors leading to increased neuronal excitability. Immunoglobulin G/albumin extravasation in the brain following BBB breakdown can activate inflammatory signals and contribute to the generation of seizures and cell death, which activate further inflammation, thus establishing a vicious cycle contributing to the development of epilepsy. ${ }^{17}$ Recently, inflammatory markers have been shown to be associated with ESES in 11 children. ${ }^{14}$ Furthermore, HSV triggers Toll-like receptors (TLRs), which are critical for antiviral immunity. ${ }^{19,20}$ The TLR signaling pathways are prototypical inflammatory pathways activated in response to pathogens (HSV) or danger signals. ${ }^{17}$ In particular, TLR3 is expressed in the CNS, where it is required to control HSV-1. ${ }^{19,20}$ Therefore, TLR3 signaling defects are specific for susceptibility to HSV-1 encephalitis. ${ }^{11}$ However, it remains unclear whether TLR3 signaling defects also create a predisposition for chronic granulomatous encephalitis.

Despite the remission of clinical seizures, our patient 
later developed focal electrographic seizures and an ESES disease pattern. Moreover, the discovery of ESES 4 years after the HSV encephalitis coincided with her behavioral deterioration and academic difficulties. Electrical status epilepticus in slow-wave sleep is an age-related epilepsy syndrome with the clinical features of regression in neurodevelopment, cognitive dysfunction, and behavioral problems accompanied by continuous epileptic activity occupying more than $85 \%$ of NREM sleep..$^{16}$ Behavioral deterioration is a common clinical feature of ESES, often including hyperactivity, aggression, emotional lability, poor peer relations, and autistic behavior. Treatment options for ESES include antiepileptic drugs (valproic acid, ethosuximide, levetiracetam, benzodiazepines), intravenous immunoglobulin, oral corticosteroids, and ketogenic diet. ${ }^{2,3,16}$ While the medical treatment of ESES has been disappointing in terms of achieving long-term remission, the disorder may initially respond to antiepileptic drug treatment, although relapse can occur.

Despite the indication of underlying symptomatic and focal origin, resective epilepsy surgery is underutilized for patients with drug-resistant ESES. Patients with congenital or perinatally acquired lesions can present with ESES without any persistent focal abnormality despite a history of focal seizures and epileptogenic lesion. Therefore, epilepsy surgery is not often considered by caregivers and treating physicians in the absence of clear epileptic focus on EEG. The pathophysiology of EEG findings of ESES remains unclear; however, the location, etiology, underlying pathology, age at the time of injury, and size of the lesion may be relevant to explain complex EEG features. ${ }^{5,9}$

Recent clinical reports describing the role of epilepsy surgery for ESES are encouraging in terms of the outcome. Clinical review of 575 patients presenting with ESES demonstrated that epilepsy surgery is the most effective treatment modality when a structural lesion is present. ${ }^{15}$ The results of another study supported this observation, reporting seizure freedom and resolution of ESES in 10 patients with a unilateral brain lesion. ${ }^{9}$ Resective epilepsy surgery including lobectomy or lesionectomy were beneficial for the resolution of EEG findings and cognitive function. Disconnective surgical procedures such as hemispherectomy and corpus callosotomy are effective for extensive unilateral or bilateral brain abnormalities acquired during the perinatal period. ${ }^{8,12,15}$ Recent clinical reports have highlighted the importance of epilepsy surgery for a good clinical outcome even in the presence of bihemispheric or generalized spike discharges accompanied by an epileptogenic lesion.

\section{Conclusions}

In summary, HSV-1 encephalitis is an acute CNS infection; however, it can cause a chronic disease in children. Following the initial clinical recovery with treatment, focal epilepsy and epileptic encephalopathy can develop over time and often remain refractory to antiepileptic drug therapy. In only a few patients, chronic granulomatous changes have been reported during the clinical course. Progressive changes in EEG recordings and seizures may alter neurodevelopment and behavior. Our patient's clinical history highlights 1) the potential role of chronic granulomatous inflammation associated with epileptic encephalopathy years after the diagnosis of HSV encephalitis and 2) the reversible course of epileptic encephalopathy accompanied by ESES following resective epilepsy surgery in the presence of symptomatic etiology.

\section{References}

1. Adamo MA, Abraham L, Pollack IF: Chronic granulomatous herpes encephalitis: a rare entity posing a diagnostic challenge. J Neurosurg Pediatr 8:402-406, 2011

2. Arts WF, Aarsen FK, Scheltens-de Boer M, Catsman-Berrevoets CE: Landau-Kleffner syndrome and CSWS syndrome: treatment with intravenous immunoglobulins. Epilepsia 50 (Suppl 7):55-58, 2009

3. Buzatu M, Bulteau C, Altuzarra C, Dulac O, Van Bogaert P: Corticosteroids as treatment of epileptic syndromes with continuous spike-waves during slow-wave sleep. Epilepsia 50 (Suppl 7):68-72, 2009

4. Chang Y, Soffer D, Horoupian DS, Weiss LM: Evolution of post-natal herpes simplex virus encephalitis to multicystic encephalopathy. Acta Neuropathol 80:666-670, 1990

5. Gupta A, Chirla A, Wyllie E, Lachhwani DK, Kotagal P, Bingaman WE: Pediatric epilepsy surgery in focal lesions and generalized electroencephalogram abnormalities. Pediatr Neurol 37:8-15, 2007

6. Hackney JR, Harrison DK, Rozzelle C, Kankirawatana S, Kankirawatana P, Palmer CA: Chronic granulomatous herpes encephalitis in a child with clinically intractable epilepsy. Case Rep Pediatr 2012:849812, 2012

7. Jay V, Becker LE, Blaser S, Hwang P, Hoffman HJ, Humphreys R, et al: Pathology of chronic herpes infection associated with seizure disorder: a report of two cases with tissue detection of herpes simplex virus 1 by the polymerase chain reaction. Pediatr Pathol Lab Med 15:131-146, 1995

8. Kallay C, Mayor-Dubois C, Maeder-Ingvar M, Seeck M, Debatisse D, Deonna T, et al: Reversible acquired epileptic frontal syndrome and CSWS suppression in a child with congenital hemiparesis treated by hemispherotomy. Eur J Paediatr Neurol 13:430-438, 2009

9. Loddenkemper T, Cosmo G, Kotagal P, Haut J, Klaas P, Gupta A, et al: Epilepsy surgery in children with electrical status epilepticus in sleep. Neurosurgery 64:328-337, 2009

10. Love S, Koch P, Urbach H, Dawson TP: Chronic granulomatous herpes simplex encephalitis in children. J Neuropathol Exp Neurol 63:1173-1181, 2004

11. Maglione PJ, Simchoni N, Cunningham-Rundles C: Toll-like receptor signaling in primary immune deficiencies. Ann N Y Acad Sci 1356:1-21, 2015

12. Peltola ME, Liukkonen E, Granström ML, Paetau R, Kantola-Sorsa E, Valanne L, et al: The effect of surgery in encephalopathy with electrical status epilepticus during sleep. Epilepsia 52:602-609, 2011

13. Schutz PW, Fauth CT, Al-Rawahi GN, Pugash D, White VA, Stockler S, et al: Granulomatous herpes simplex encephalitis in an infant with multicystic encephalopathy: a distinct clinicopathologic entity? Pediatr Neurol 50:392-396, 2014

14. van den Munckhof B, de Vries EE, Braun KP, Boss HM, Willemsen MA, van Royen-Kerkhof A, et al: Serum inflammatory mediators correlate with disease activity in electrical status epilepticus in sleep (ESES) syndrome. Epilepsia 57:e45-e50, 2016

15. van den Munckhof B, van Dee V, Sagi L, Caraballo RH, Veggiotti P, Liukkonen E, et al: Treatment of electrical status epilepticus in sleep: A pooled analysis of 575 cases. Epilepsia 56:1738-1746, 2015

16. Veggiotti P, Pera MC, Teutonico F, Brazzo D, Balottin U, Tassinari CA: Therapy of encephalopathy with status epilepticus during sleep (ESES/CSWS syndrome): an update. Epileptic Disord 14:1-11, 2012 
17. Vezzani A, Aronica E, Mazarati A, Pittman QJ: Epilepsy and brain inflammation. Exp Neurol 244:11-21, 2013

18. Viñas JM, Gonzalez MJ, Ribes AG, Expósito RG, Bragado FG: Postencephalitic chronic granulomatous disease. Pediatr Neurol 35:297-299, 2006

19. Zhang SY, Jouanguy E, Sancho-Shimizu V, von Bernuth H, Yang K, Abel L, et al: Human Toll-like receptor-dependent induction of interferons in protective immunity to viruses. Immunol Rev 220:225-236, 2007

20. Zhang SY, Jouanguy E, Ugolini S, Smahi A, Elain G, Romero $P$, et al: TLR3 deficiency in patients with herpes simplex encephalitis. Science 317:1522-1527, 2007

\section{Disclosures}

The authors report no conflict of interest concerning the materials or methods used in this study or the findings specified in this paper.

\section{Author Contributions}

Conception and design: Akman, Taskin. Acquisition of data: Akman, Tanji, Feldstein, McSwiggan-Hardin. Analysis and interpretation of data: Akman, Tanji, Feldstein. Drafting the article: Akman, Taskin. Critically revising the article: Akman, Taskin, Tanji. Reviewed submitted version of manuscript: Akman, Taskin. Approved the final version of the manuscript on behalf of all authors: all authors.

\section{Supplemental Information}

\section{Previous Presentations}

Portions of this work were presented in poster form at the 70th American Epilepsy Society Annual Meeting held in Houston, Texas, on December 2-6, 2016.

\section{Correspondence}

Cigdem I. Akman, Department of Neurology, Division of Child Neurology, Columbia University Irving Medical Center, 180 Fort Washington Ave., Harkness Pvl. Rm. 550, New York, NY 10032. email: cia11@cumc.columbia.edu. 